\title{
Vigilantism in Science: The Need and the Risks
}

\author{
Jaime A. Teixeira da Silva \\ P. O. Box 7, Miki-cho post office, Ikenobe 3011-2, Kagawa-ken, 761-0799, Japan \\ Email:jaimetex@yahoo.com
}

\section{Doi:10.5901/ajis.2016.v5n3p9}

\begin{abstract}
Science is in a constant state of flux. In recent years, science and scientists have been coming under attack, and scrutiny, by internal and external skeptics and critics, as well as a potentially anti-science movement. Despite this fairly negative portrayal, the expected outcome is that science - and its players - will become more robust, more critical and thus more reliable and accountable, i.e., that there will be a positive light at the end of a tumultuous period of challenge, although we are still far from reaching that point. Part of this process involves individuals or groups, known or anonymous, who are actively seeking out faults or errors, to demonstrate that science and scientists, and journals and publishers, are flawed and that something needs to be done to rectify this. Very rarely are such individuals referred to as vigilantes, but in essence, this is in fact what they are: individuals who have taken the reigns of quality control where it has failed, or where it has perceived to have failed. Vigilantism, which tends to conjure images of mob squads or self-appointed policing figures, involves taking on community style group awareness and implementation of their own rules, morals and values, as they see fit. Vigilantism, in the era of post-publication peer review, has reached science. This paper examines the positive and negative role that vigilantism plays, or can play, in science.
\end{abstract}

Keywords: anti-science; critical; flawed scientific discovery; legend; vigilante

\section{How Might Vigilantism have been Born in Science?}

There is a growing and politically powerful anti-science movement (Otto 2012). One could thus say that this group of critics and skeptics may have led to the birth of the concept of vigilantism in science. Scientific denialism (Diethelm and McKee 2009) has both religious and ideological fundamentalist roots, and stems from actual or perceived risks that scientific discoveries may pose to society and humanity. In essence, the anti-science movement, which may originate from the top (Rigden and Stuewer 2012), will counter the positive aspects of science with politically motivated criticisms and with documented failures such as industrial mishaps, environmental scandals, biological conclusions that may contradict religious beliefs, and failed medical trials where the patients have become the victims. It is not easy to clearly distinguish between an anti-science posture, or simply a critical view, without knowing the trajectory of ideas by that individual over time, and thus both terms will be used loosely and interchangeably within this paper. On the other hand, there is a class of individuals, both scientists and not, who have seen that the channel for scientific discovery, namely scientific journals, may be more flawed than was originally thought. Such flaws, which can range from imperfect reviews to unqualified peer reviewers or biased editorial decisions (Teixeira da Silva and Dobránszki 2015a), or the expansion of academically suspect journals (Eriksson and Helgesson 2016), can ultimately lead to less than perfect science being published, and undermine trust in science and in its reported discoveries. Such flaws also work into the hands of science critics and the anti-science movement. As a result, a new class of science skeptics and science critics has emerged, even from within the scientific ranks. Some of these are scientists who may have dropped out of science because they were disenchanted with the prospects and the opportunities. Others may have been disillusioned with the power imbalance vested in the status quo or technocrats over many matters related to science or science governance, giving junior scientists little chance to enact reform, in particular in a field of study that would directly affect their careers and research. Others yet may have witnessed, or been victims of, a narcissistic top-down structure in a laboratory or research institute (Lemaitre 2016), unable to subject themselves to a psychologically demoralizing environment, opting instead to turn to criticism to vent their frustration. Thus, the core emotions that have led to the rise of vigilantism in science tend to be frustration, anger, disappointment, rebellion and disgust, among others. Increasing retractions that document more and more errors in the literature, increasing cases of misconduct, as well as greater awareness through blogs and social media such as Twitter, are fueling the anti-science philosophy and aiding its spread. In many cases, the concerns are valid, but in others, the intentions may simply be to cause harm, tarnish images, and spread innuendo. Thus, science 
critics, the anti-science movement and vigilantism are essential but also pose fundamental risks to science's integrity and survival, the greatest being their influence on policy making. In the current anti-science movement, such individuals are referred to as science watchdogs, a topic will be briefly explored in the next letter. Otto (2012) accurately states that "Policy is determined by the loudest voices, reducing us to a world in which might makes right - the classic definition of authoritarianism." And it is precisely for this reason why greater attention is required by scientists to the anti-science movement, which can range from racists, sexists, creationists, economic conservatives and lobbyists (Rationalwiki, 2016), so as to be able to distinguish valid academic vigilantism that spurs accountability from vigilantism that aims purely to destroy science and scientists' reputations.

\section{How did Vigilantism Enter the Scientific Conversation?}

Vigilantism only crept into the scientific debate as a formal term in 2015 when Prof. Michael Blatt, Regius Professor of Botany at the University of Glasgow, and Editor-in-Chief of the journal Plant Physiology, called out the destructive nature of anonymous commenting at PubPeer (www.pubpeer.com), a site that allows for post-publication peer review (PPPR) of the published literature, indicating that "the overwhelming majority of posts on PubPeer are negative and occasionally malicious" and describing the platform as "The self-assumed role of PubPeer is about policing, not discussion." The introduction of the vigilante mentality of the PPPR movement at PubPeer was further solidified by his comment "Legitimate authority demands consensual recognition and identity, both currently lacking for PubPeer." The label of a vigilante site was cemented by Blatt with this comment: "Indeed, if there is a threat to the scientific process, I would argue that, unchecked, the most serious is the brand of vigilante science currently facilitated by PubPeer." The underlying threat emerged, as Blatt saw it, from unregulated comments by anonymous commentators, an issue that has both positive and negative aspects in PPPR (Teixeira da Silva and Blatt, 2016). However, the fact that a criticism of the need to be vigilant of the scientific literature and the publishing process became interlaced with criticisms of PubPeer as a PPPR platform, criticisms of the founders, Brandon Stell, Richard Smith, and George Smith, and of Stell's colleagues, Boris Barbour and Gabor Brasnjo (Blatt, 2016), as well as criticisms of anonymity, has led to an unclear understanding of what vigilantism in science is, or should be. In the next section, I attempt to decode what vigilantism is in the context of science publishing.

\section{What is Scientific Vigilantism?}

To build my argument and my definition, I rely on two web sources to build my basal definition, despite their fluctuating and potentially unreliable content, Wikipedia (2016) and thefreedictionary.com (2016). Using arguments from those sources, I hope to establish and clarify what science vigilantism is since no literature appears to have been published on this topic yet, even less so within the context of science, other than an allusion to the topic by Blatt. Thefreedictionary.com (2016) defines vigilantism as "Taking the law into one's own hands and attempting to effect justice according to one's own understanding of right and wrong; action taken by a voluntary association of persons who organize themselves for the purpose of protecting a common interest, such as liberty, property, or personal security; action taken by an individual or group to protest existing law; action taken by an individual or group to enforce a higher law than that enacted by society's designated lawmaking institutions; private enforcement of legal norms in the absence of an established, reliable, and effective law enforcement body." To give it a scientific PPPR setting, I modify this definition as follows to deemphasize the legal aspect and to incorporate a scientific prism: "Taking scientific quality control (QC) into one's own hands and attempting to effect QC according to one's own understanding of right and wrong; action taken by a voluntary group of persons, scientists or not, who organize themselves for the purpose of protecting a common interest, namely science; action taken by an individual or group to protest the existing scientific publishing platform; action taken by an individual or group to enforce a higher scientific standard than that enacted by society's designated scientific and/or publishing institutions; private enforcement of publishing norms in the absence of an established, reliable, and effective enforcement body for publishing norms." Of note, scientific vigilantism will involve scientific activism (i.e., the protest against something that is wrong in science) and scientific whistle-blowing (i.e., the public revelation of facts that are otherwise confidential but that could potentially damage science, or reputations, or bring about clarity), but is not necessarily equated with these concepts. Wikipedia defines a vigilante as "a civilian or organization acting in a law enforcement capacity (or in the pursuit of self-perceived justice) without legal authority." Thus both the Wikipedia (2016) and the Thefreedictionary.com (2016) definitions refer to the law and how vigilantism is a movement that counters the law by individuals or groups without formal authority.

I thus propose a broad definition of scientific vigilantism, as follows: the statements or actions taken by scientifically 
qualified or unqualified persons, anonymous or not, individuals or groups, with or without conflicts of interest and biases, with the purpose of exposing errors, conflicts or issues in science and science publishing that were created or allowed by established and recognized scientific authorities, primarily editors, journals and publishers, but not exclusively this status quo, with the ultimate objective of seeking a better and corrected scientific literature, greater transparency and accountability. Scientific vigilantism seeks justice for those who were negatively affected by flaws in scientific QC, and fair repercussions for those who allowed such flaws to come into existence, and persist. At base, scientific vigilantism does not seek to use illegal or violent / armed means to achieve its end, but may rely on scientific activism and whistle-blowing to achieve its final objectives. Such actions will involve the direct criticism of scientists, editors, journals and publishers, through blogs, Tweets, other social media, including sites such as PubPeer or PubMed Commons (http://www.ncbi.nlm.nih.gov/pubmedcommons/), or published papers.

At base, an increase in the militarization of science and the subsequent criminalization of scientists (Teixeira da Silva 2016a) is adding a new layer of complexity to science that is stimulating extreme actions, viewpoints and measures to deal with conflicts and problems, including the widening of vigilantism.

\section{The Pro's and Con's of Scientific Vigilantism}

The failure of peer review has often been blamed on the lack of reproducibility, but the ultimate fault for the lack of reproducibility is itself in the weaknesses and flaws of traditional peer review, where insufficient scrutiny by editors and peers has led to the publication of a potentially large tranche of flawed scientific papers harboring, or not, misconduct, but most certainly many errors. When the basic mechanism that is meant to safe-guard the literature's quality and integrity, i.e., peer review, has failed, reproducibility takes a back seat (Teixeira da Silva 2016b). In such a case, holding authors, editors, and publishers accountable for what they have published becomes the responsibility of the scientific community and the public, even after authors have deceased (Teixeira da Silva 2016c; Teixeira da Silva and Dobránszki 2015b). This step, PPPR, in which errors are accidentally discovered or are intentionally searched for, involves the effort of vigilant readers to ensure that the academic record is corrected after alerting the authors and appropriate editors and publishers. In cases where authors, editors and publishers fail to respond, public shaming may be required to alert the public to this lack of responsibility and to force change, requiring the actions of vigilantes. At base, vigilantism in the context of science publishing serves a positive "pressure" of ensuring accountability and correction of the literature.

Conversely, vigilantism may also have negative repercussions, including a negative stigma and destroyed reputations as a result of shaming (Armfield et al. 2016). In journals where a rigorous peer review takes place, the process can often be stressful and exhausting, having to respond to the critiques of known and unknown peers. So, traditionally, authors are not accustomed to being questioned about their papers after these have been published even though publishing is meant to be an open-ended conversation. Consequently, queries that arise, anonymously or not, after a paper is published, can be a surprise - or shock - to many - if not most - authors, and can constitute a level of stress. Vigilantism and vigilantes may be oblivious, or insensitive, to this stress. To date, being held accountable for what one has published has rarely been challenged save for blatant cases of misconduct, so the PPPR movement and the action of vigilantes has introduced a new layer of stress for scientists. Although scientists need not feel the need to be looking over their shoulders if they know that they have not dabbled in misconduct, the notion that one's work can be challenged, even after death, and even for minor errors, is an unsettling feeling since the motives of those challenging the literature are usually unknown, primarily because biases exist in editorial and publisher ranks, and since a fair defense is not always possible. Although vigilantism may be pushing scientists towards more careful record taking, analysis and interpretation of results and publication of papers, it is also pushing scientists to feel more fearful and threatened. Vigilantism is thus introducing a layer of aggression, insecurity and instability into science. Blatt (2015) provides a few more arguments about how uncontrolled and unmoderated commenting on sites like PubPeer can be damaging, simply by association with the site, or by the tone associated with comments that have been poorly moderated. This vigilantism mentality of PubPeer is reinforced by Buranyi (2016), who describes PubPeer as serving as "a sort of 4chan for science, allowing anyone to post anonymous comments on scientific studies. Originally intended as a forum for the discussion of methods and results, PubPeer has perhaps become best known as a clearinghouse for accusations of scientific error, fraud, and misconduct-forcing journals to issue corrections and retractions, damaging careers, and eventually embroiling the site in a court case in which it's advised by Edward Snowden's legal team at the American Civil Liberties Union." However, in recognition of the its conflicting role, Buranyi further states of PubPeer "In the view of its critics, PubPeer enables an unchecked stream of accusations with no accountability. But to its supporters, PubPeer is maybe the only consistently effective way to expose fraud and error in the current scientific system." Given these new pressures 
on the scientific authorship, authors' rights need to be urgently reassessed (Al-Khatib and Teixeira da Silva 2016) in the context of PPPR and in the face of vigilantism's risks and intended or unintended consequences.

\section{Disclaimer and Conflicts of Interest}

The author is both a vigilant scientist and a science vigilante which can automatically create a potential conflict of interest with any scientist whose work he has scrutinized, or with any editor or publisher he has criticized.

\section{References}

Al-Khatib, A., Teixeira da Silva, J.A. (2016) What rights do authors have? Science and Engineering Ethics (in press) DOI: 10.1007/s11948-016-9808-8

Armfield, S.W.J., Armfield, D.M., Franklin, L.O. (2016) The shaming: creating a curriculum that promotes socially responsible online engagement. In: Papa, R., Eadens, D.M., Eadens, D.W. (eds.) Social Justice Instruction, Springer International Publishing, Switzerland, pp. 271-280. doi: 10.1007/978-3-319-12349-3_24

Blatt, M.R. (2015) Vigilante science. Plant Physiology 169(2), 907-909. Doi: 10.1104/pp.15.01443

Blatt, M.R. (2016) When is science 'ultimately unreliable'? Plant Physiology 170(3), 1171-1173. Doi: 10.1104/pp.16.00160

Buranyi, S. (2016) Anonymous internet vigilantes are taking peer review into their own hands. http://motherboard.vice.com/en_uk/read/anonymous-internet-vigilantes-are-taking-peer-review-into-their-own-hands-pubpeer (last accessed: 18 October, 2016)

Diethelm, P., McKee, M. (2009) Denialism: what is it and how should scientists respond? The European Journal of Public Health 19(1), 2-4. Doi: 10.1093/eurpub/ckn139

Eriksson, S., Helgesson, G. (2016) The false academy: predatory publishing in science and bioethics. Medicine, Health Care and Philosophy (in press) DOI: 10.1007/s11019-016-9740-3

Lemaitre, B. (2016) An essay on science and narcissism: how do high-ego personalities drive research in life sciences? Self-published, $270 \mathrm{pp}$.

Otto, S.L. (2012) Antiscience beliefs jeopardize U.S. democracy. Scientific American online. http://www.scientificamerican.com/article/antiscience-beliefs-jeopardize-us-democracy/ (last accessed: 18 October, 2016)

Rationalwiki (2016) Antiscience. http://rationalwiki.org/wiki/Antiscience (last accessed: 18 October, 2016)

Rigden, J.S., Stuewer, R.H. (2012) Anti-science: it comes from the top. Physics in Perspective 14(4), 389-391. Doi: 10.1007/s00016012-0103-z

Teixeira da Silva, J.A. (2016a) The militarization of science, and subsequent criminalization of scientists. Journal of Interdisciplinary Medicine 1(2): 214-215. DOI: 10.1515/jim-2016-0031

Teixeira da Silva, J.A. (2016b) Reproducibility: does it really matter? The Winnower 3: e146575.50444. 3. pp. DOI: 10.15200/winn.146575.50444

Teixeira da Silva, J.A. (2016c) An error is an error... is an erratum. The ethics of not correcting errors in the science literature. Publishing Research Quarterly (in press) DOI: 10.1007/s12109-016-9469-0

Teixeira da Silva, J.A., Blatt, M.R. (2016) Does the anonymous voice have a place in scholarly publishing? Plant Physiology 170(4): 1899-1902. DOI: 10.1104/pp.15.01939

Teixeira da Silva, J.A., Dobránszki, J. (2015a) Problems with traditional science publishing and finding a wider niche for post-publication peer review. Accountability in Research: Policies and Quality Assurance 22(1): 22-40.

Teixeira da Silva, J.A., Dobránszki, J. (2015b) The authorship of deceased scientists and their posthumous responsibilities. Science Editor 38(3/4): 98-100.

Thefreedictoniary.com (2016) Vigilantism. http://legal-dictionary.thefreedictionary.com/Vigilantism (last accessed: 18 October, 2016)

Wikipedia (2016) Vigilante. https://en.wikipedia.org/wiki/Vigilante (last accessed: 18 October, 2016). 